\title{
Expectations to data: Perspectives of service providers and users of future health and wellness services
}

\author{
Juha Häikiö $^{1}$ - Sari Yli-Kauhaluoma ${ }^{2,5}$ (1) $\cdot$ Minna Pikkarainen ${ }^{1,3,4} \cdot$ Marika livari $^{3} \cdot$ Timo Koivumäki $^{3}$
}

Received: 8 October 2019 / Accepted: 16 January 2020 / Published online: 21 January 2020

(C) The Author(s) 2020

\begin{abstract}
The healthcare and wellness sector currently attempts to provide more proactive service models with data-driven solutions. This study examines the expectations and values related to personal data i.e. data valences from the perspective of service providers and individual users. The study is based on the analysis of extensive empirical material collected through interviews and a collaborative workshop. The data was collected in one cultural context, Finland. The results suggest that the potential service providers and users have similar expectations regarding self-evidence of data while the main differences concern the expectations of transparency. The results of the study propose some basic requirements for the development of personalised data-driven services in future. The study suggests that basic requirements for the development of future data driven services concern expectations to usable data visualisations, data as a motivator, data accuracy and data transparency. Even though there are varying expectations to personal health data and even some concerns, it can be seen that here different ecosystem actors primarily perceived the wider use of personal health and wellness data as a positive trend. It can be concluded that collaborative personal data-driven service ecosystems are an integral part of development towards proactive service models in healthcare.
\end{abstract}

Keywords Health data $\cdot$ Wellness data $\cdot$ Personal data $\cdot$ Data expectations $\cdot$ Data valence

Juha Häikiö

juha.haikio@vtt.fi

Sari Yli-Kauhaluoma

sari.yli-kauhaluoma@aalto.fi

Minna Pikkarainen

minna.pikkarainen@oulu.fi

Marika Iivari

marika.iivari@gmail.com

Timo Koivumäki

timo.koivumaki@oulu.fi

1 VTT Technical Research Centre of Finland Ltd, Oulu, Finland

2 Department of Management Studies, School of Business, Aalto University, Espoo, Finland

3 Oulu Business School, University of Oulu, Oulu, Finland

4 Medical Imaging Physics and Technologies, University of Oulu, P.O. Box 4600, 90014 Oulu, Finland

5 University of Helsinki, Centre for Consumer Society Research, Helsinki, Finland

\section{Introduction}

A current trend in healthcare highlights the transformation from a reactive to a proactive service model [1] and towards data-driven care [2]. This new trend assumes that individuals are increasingly using health apps, wearable devices and integrated sensors that continuously generate vast amounts of data (e.g. sleep, food, exercise and blood sugar) to be used either by individuals themselves [3] for self-reflection or behaviour change $[4,5]$ or by service provider organizations as a valuable asset [6] for novel or extended services.

The key idea behind the new service model is the suggestion that the focus should shift from reactive disease treatment to proactive wellness maintenance, emphasising, e.g. an individual- instead of population-based disease diagnosis [7]. This suggestion implies that there is change in emphasis from hospital monitoring to self-monitoring and from clinical diagnostics to self-diagnostics. Flores et al. [8] suggest that science-based healthcare by and large moves from clinics into patients' homes and workplaces. All this means that the role of an individual will equally change from a passive subject to an active collaborator in the healthcare sector [9]. At best then, a range of innovations will create supporting services around the needs of individuals in a 
manner that is highly personalised [5]. The crucial element in the change of a service model is personal data as it acts as a basis for the development of new services that are relevant from the perspective of individual's health and wellbeing.

A path towards the more proactive approach in healthcare demands new services that are based on different types of actors' contributions to collaboration around health data, as opposed to a straightforward and traditional firm-centric perspective on service innovations (see e.g. [10]). The new healthcare service model and the necessary data flow leads, however, to new kinds of challenges that begin with the identification and alignment of expectations for personal data between service providers and users.

Research regarding such expectations combining the perspectives of individuals and organizational actors such as health service providers, insurance service providers and health technology providers that all either create, share, store or use personal data, is, however, so far relatively scarce. There are only few existing studies focusing on data expectations [11], needs [12], and requirements $[13,14]$ from the perspective of both individuals and organizational actors. The existing studies focusing on data and related technologies from the perspective of individuals often focus mainly on quantified self-tracking [15], new service adoption [16] or data usage of online patient communities [17]. The organizational perspective again has mainly been just on health data security issues [18].

The aim of this paper is to study expectations to personal health and wellness related data from the perspectives of both individuals and various private service providers in health and wellness sector. The study applies the typology of data valences [11] as a framework for analysing data expectations from the perspectives of different health and wellness data related actors in the potential service ecosystem context (see [19]). The concept of data valences emphasizes the differences in expectations and values regarding to data in different contexts and perspectives. These differences can manifest, for instance, in expectations regarding a) self-evidence (does data require interpretation by experts); b) actionability (what kind of data is involved and when can it serve as the basis for decision-making about interventions or behaviour change); c) connection (can the data offer a space for conversation); d) transparency (how can the data be accessed and shared); e) truthiness (what kind of data feels true); and f) discovery (can the data offer a window into understanding health and disease) [11]. The recognition of these areas of potential variation is important, as tensions may emerge between different actors, such as the users of digital devices and healthcare experts, due to their varying expectations and the hopes that they place on the data [11].

The study is based on a qualitative study that includes a careful analysis of extensive empirical material collected through eleven interviews with nine private organisations that have an intention to use health and wellness data as a basis for their future service development. A collaborative workshop was organised for the representatives of these organizations to extend the interviews. In addition, data was analysed from interviews of five medical doctors working in public hospitals. Additionally, the study contains 48 interviews with individuals participating on a large health and wellness pilot initiative on digital health. Data collection for the study was done with organizations operating in Finland and individuals living in Finland.

\section{Background}

Earlier studies have explored health data from, e.g. the perspectives of the patient and healthcare service provider [20], insurer [21], big data analytics [22] and business models overall [23]. In general, the rapid development of technologies has raised expectations about the possible use of health-related data in the medical sector [24]. These expectations are typically related to the versatility of sensors and algorithms, extensibility with new type of sensors and algorithms, safety in data usage and dependability in different environments [14].

Shapiro et al. [25] suggest that patient-generated health data complements data across the health system, including that of healthcare providers and other stakeholders. Self-monitoring data may enhance communication between the patient and service provider, offering not only personalised plans but also patient education [26]. Technical, privacy and security issues regarding patient-related health data obtained from outside clinical settings have, however, given rise to concerns among healthcare service providers [27]. Patients may have unrealistic expectations for how data is used. They might like to obtain a complete picture of daily life through data, receive personalised and actionable treatment plans based on data, and make data support certain affective needs (e.g. self-awareness and emotional support) [20]. Additionally, concerns may arise particularly in relation to the collection and usage of personal medical information, such as medical records and medical history [24]. From the perspective of medical professionals, barriers related to an effective use of person-generated data include, for instance, a lack of time to process detailed records, questions about the validity of the data, doubts regarding the benefits gained by using the data, and individuals' lack of self-monitoring tools with workable data-sharing capabilities [26]. More severe issues relate to violations and abuses of patient privacy, highlighting the sensitive nature of medical information [24].

Fiore-Gartland and Neff (2015) have importantly noted that individuals and different service providers may have varying expectations to health and wellness related data. The concept of data valences emphasizes such differences in expectations and values regarding to data in different contexts and perspectives. Fiore-Gartland and Neff [11] have identified differences in expectations regarding the aspects of self-evidence, actionability, connection, transparency, truthiness, and discovery of data. 
The self-evidence aspect ponders whether data is expected to be self-evident or whether it is considered to require at least some interpretation by experts. A whole other question is whether experts possess the ability to interpret some specific data [26]. Making data self-evident for both individuals and service providers may require active co-interpretation [28] based on simple and understandable presentations of data [29], and sometimes even separate data visualisations for individuals such as patients and service providers [30].

Actionability discusses expectations on the type of data that may act as a basis for decision-making about interventions or behaviour change [11]. Actionability is highlighted in recent studies on wearables and their abilities to produce sensor data to influence human behaviour [31, 32] as well as contextualised feedback [33]. Miyamoto et al. [34] emphasize the importance of connecting data with its context and meaning to promote behaviour change. Taking action upon the selftracking data can, however be challenging without professional support. Overall, it is reflection that is considered as critical element for people to move from examination of personal data to action [35]. For this purpose, Kocielnik et al. [36] propose a dialog solution for systematic reflection on self-tracking data with the aim for more durable changes in health behaviour among personal fitness trackers' users.

Connection refers to the idea whether data offers a space or a starting point for a conversation between different actors in health and wellness network [11]. Patient portals [37] and patient-generated health data $[25,38]$ are some examples of data spaces that at best may promote communication between patient and service provider. In general, data-driven consultation may facilitate in-depth conversations between service provider and patient [39]. When patient-generated data can be accessed already before the clinical visit by a service provider it can be used to plan the clinical visit agenda and to identify a topic to focus the discussion on better [40].

Expectations on data transparency focuses on aspects of data access and distribution [11]. Data transparency is highlighted as one of the key enablers regarding transforming health care delivery [41]. Therefore, questions about the ownership of medical data from the viewpoint of individuals [42], open data [43], and accessibility of personal health data [44, 45 ] are of utmost importance. There can be challenges regarding health data transparency related to patient-generated data in clinical practice as laws strictly regulate the use of medical data prohibiting its integration with patient-generated data [46]. From the perspective of insurance companies there are particular needs for data transparency and trust building as customers need assurance that their personal health data will not be used against them [47].

There are also differences in expectations regarding the truthiness of data referring to the question of what kind of data feels true [11]. This issue is highly relevant in digital self-tracking that produce quantitative data for device users
[48]. In a clinical visit, self-tracking health data can be helpful for the physician especially when a patient has difficulties to express a clear reason for the visit [40]. West et al. [49] confirm that patient-generated data promotes making decisions about further physical examination, but it is not alone sufficient for medical intervention partly due to its unknown accuracy. Current personal informatics tools available for personal data collection have variation in data accuracy, which sets requirements also for users to find personal strategies for making the data accountable [50]. All these aspects have direct effects on the feelings of truthiness of data.

Finally, the aspect of discovery discusses whether data is expected to offer a window into better understanding of health and disease [11]. Wicks [51] has noted that individuals without formal scientific or medical training are increasingly selfexperimenting and even creating self-experiment health related online communities by using various digital tools and devices. Sometimes, people have no specific goal when they start self-tracking but instead, they try to identify patterns from self-tracking data to enable them to identify how body responses to various stimuli [15]. Mamykina et al. [52] have noted that self-monitoring data may provide a starting point for personal discovery of cause and effect in serious illnesses such as diabetes, which can lead to positive behavioural changes. Karkar et al. [53] have even developed a selfexperimentation framework for testing health-related hypotheses with person-generated health and wellness data. Similarly, Daskalova et al. [54] have presented an approach for discovering effects of behaviour change with the aid of self-tracking devices, and provided a set of guidelines for those who conduct self-experiments to reach better health.

\section{Methods}

This study was conducted as a qualitative research project [55] and applies the data valences typology developed by FioreGartland \& Neff [11] as a framework for analysing the expectations and values regarding personal data from the perspective of both individuals and various service providers in an emerging health and wellness ecosystem.

The concept of ecosystems has developed as a way to address the complexities and dynamic relations between organisations in the modern business landscape [56, 57]. In datadriven service ecosystems, data is the dynamic resource used to generate value and create new markets to an extent that a single company would not be able to do on its own [58]. The concept of service ecosystems as applied using a servicedominant logic draws attention to the collaborative creation of value, i.e. to the co-creation of value [19]. The actors explored in this study consist of an emerging ecosystem of service providers who are interested in the utilization of personal health and wellness related data in future preventive 
healthcare services as well as individuals who already during the course of the study generated and used such personal data for various daily purposes.

\subsection{Empirical study with health and wellness service providers}

Empirical data from business actors was collected in two ways. First, we organised eleven company-specific, semistructured interview sessions [59], and fifteen representatives from nine separate organisations were interviewed either personally or via phone during the summer and autumn of 2016 . Eleven interviews were organised as personal interview sessions. Additionally, we organised five group interview sessions where two interviewees from the same company participated together in one interview session. These sessions consisted of interviews of nurses, representatives of an insurance company, representatives of a wellness training company, and representatives of another wellness company. One representative of the insurance company was interviewed in two separate sessions with a different colleague. A main theme of the interviews was the use of human-centric personal wellness and health data in digital services. Since the data from first interview round included only two nurses and one medical doctor, five additional interviews were made for medical doctors in two public hospitals as a purpose to validate the key findings. At the time of the study, some of the selected actors such as insurance companies and a private healthcare company had already operated for long in the healthcare business, while large and small technology companies, a telecommunication company, and a wellness company only looked for possibilities to build novel services using personal health and wellness related data.

Second, we organised a workshop for companies interested in health and wellness services in February 2017. The workshop focused on personal data as a possible reformer of health and wellness services and business. Seven representatives from six different companies participated in the workshop. The companies were invited to the workshop since they all operated in the health and/or wellness sector and used some health- and/or wellness-related personal data in their services. All the participating companies were identified as potential participants in the emerging personal data-driven health and wellness service ecosystem. The data collected from the company interviews and workshop was transcribed and arranged using NVivo qualitative data analysis software. Table 1 presents the companies, their key offerings and the participants in the interviews and workshops.

\subsection{Empirical study with individuals}

Besides company representatives, the ecosystem also includes individuals. Thus, we also studied the consumer perspective on
Table 1 Roles and key activities of the organizational ecosystem actors

\begin{tabular}{|c|c|c|}
\hline Role & Key activities & $\begin{array}{l}\text { Organisations and } \\
\text { interviewees }\end{array}$ \\
\hline $\begin{array}{l}\text { Health service } \\
\text { provider }\end{array}$ & $\begin{array}{l}\text { Private and public sector } \\
\text { health services } \\
\text { (medical centre, } \\
\text { hospital services, an } \\
\text { online store offering } \\
\text { wellbeing services) }\end{array}$ & $\begin{array}{l}\text { Private medical centre; } \\
\text { three interviewees: two } \\
\text { nurses and one medical } \\
\text { doctor } \\
\text { Two public hospitals; five } \\
\text { interviewees: medical } \\
\text { doctors }\end{array}$ \\
\hline $\begin{array}{l}\text { Wellness service } \\
\text { provider }\end{array}$ & $\begin{array}{l}\text { Wellness services } \\
\text { (personal training and } \\
\text { nutrition coaching) }\end{array}$ & $\begin{array}{l}\text { One company offering } \\
\text { personal training } \\
\text { services and one } \\
\text { company offering } \\
\text { training courses for } \\
\text { personal trainers; } \\
\text { four interviewees: two } \\
\text { personal trainers, a CEO } \\
\text { and an executive } \\
\text { responsible for } \\
\text { international operations }\end{array}$ \\
\hline $\begin{array}{l}\text { Insurance } \\
\text { service } \\
\text { provider }\end{array}$ & $\begin{array}{l}\text { Insurance services } \\
\text { (including health-related } \\
\text { insurances) }\end{array}$ & $\begin{array}{l}\text { Two large insurance } \\
\text { companies; } \\
\text { four interviewees: chief } \\
\text { actuary, business } \\
\text { developer, digital } \\
\text { developer and a director } \\
\text { of digital development }\end{array}$ \\
\hline $\begin{array}{l}\text { Technology and } \\
\text { application } \\
\text { service } \\
\text { provider }\end{array}$ & $\begin{array}{l}\text { Development and sales } \\
\text { of data analytics and } \\
\text { wellness applications }\end{array}$ & $\begin{array}{l}\text { Two large firms developing } \\
\text { digital solutions; } \\
\text { two smaller technology } \\
\text { companies offering } \\
\text { training and wellness } \\
\text { services for their } \\
\text { customers; } \\
\text { four interviewees: head of } \\
\text { research, innovation } \\
\text { manager, a CEO and the } \\
\text { head of product } \\
\text { management }\end{array}$ \\
\hline
\end{tabular}

personal data in the health and wellness sector. The data was collected in the form of interviews within the context of a health and wellness pilot initiative in which the advancement of individuals' life-style changes played a key role. In the pilot study, various types of personal data, such as genomic, metabolomic, gut microbiomic and comprehensive life-style monitoring data, including self-tracking data, were collected over a 16-month period (from October 2015 to January 2017) from roughly 100 volunteers (see [60]). All participants had provided their signed informed and voluntary consent for the pilot study.

This study analyses the interviews that we conducted with the volunteering participants in the pilot initiative. The focus of the interviews was on pilot participants' experiences with self-tracking and self-tracking data. We interviewed a sample of the health and wellness pilot participants in two phases. The first round of interviews (27 interviewees) took place in May/ June 2016, approximately seven months after beginning of the 
pilot study, when the participants had roughly three months of experience with the personal data collection via the activity wrist watch (Withings Activité Pop), which is a self-tracking device with a connected smart phone application (Withings Health Mate). The activity wrist watch helped pilot participants collect personal data on their activity (steps) and sleep. Additionally, the pilot participants had had three health checkups at the time of the first round of interviews. The second round of interviews ( 21 of those interviewed in the first round) took place at the end of the pilot study in December 2016/ January 2017, when the pilot participants had experienced roughly 10 months of personal data collection via the activity wrist watch. Additionally, they had had five health check-ups. Two rounds of interviews of the same pilot participants was necessary to identify those expectations and values related to personal data that pilot participants seemed to emphasize. The interviewed pilot participants consisted of both inexperienced and experienced self-trackers. The age of the interviewees ranged from 28 to 57 years. In the first round of interviews, there were nine males and eighteen females; in the second round, there were eight males and thirteen females.

In the interviews, the pilot participants were asked about their use experiences with the self-tracking device in terms of personal data collection and its use. Besides self-tracking data, some of the answers also contained brief reflections on pilot participants' health data, such as insulin production, cholesterol and blood sugar. Additionally, the interviewees were asked to reflect on the potential advantages of current or future digital health services. All of the interviews were recorded and later transcribed verbatim, resulting in approximately twentyfive hours of interview material. The anonymity of the interviewees was guaranteed throughout the interview process and after its completion.

All the empirical data collected through company and individual interviews was systematically coded (see [61]) based on the six data valences identified by Fiore-Gartland and Neff [11]. The focus of the analysis was on the varying expectations of different ecosystem actors regarding the personal data. The careful reading and systematic coding of all empirical material resulted in identification and elaboration of both the differences and similarities in the expectations of the different actors regarding personal data. The rationale was also to ensure transparency and coherence [62] regarding the qualitative evidence presented in this study [63].

\section{Expectations to personal health and wellness data: Perspectives of service providers and users}

This section presents the findings from the interviews and the workshop conducted with various domain experts and individuals using personal health and wellness data.

\subsection{Self-evidence}

The self-evidence of data highlights the fact that data speaks for itself without a need for time-consuming data interpretation by experts [11]. Both service actors and individuals made numerous comments regarding self-evidence of data. One of the interviewed medical doctor noted that the amount of personal data that people bring to a doctor's appointment has clearly increased during the last decades. In general, she considered the availability of rich personal and other healthrelated data as positive, but warned about the increasing tendency of people to do self-diagnosis, which could result in misinterpreting the data:

'Sometimes people get worried about their health situation due to their own data interpretation ... a person can monitor the heart rate while running. Suddenly, there is a technical problem with the measurement device and the person sees completely incorrect numbers. Then, the person begins to fear [that they] have some heart problems.' (Medical doctor in a health service provider)

The interviewed health professionals stressed in their group interview that their competencies are needed in data interpretation and for making a diagnosis. It was revealed in four medical doctor interviews, that the current medical systems are often too slow and difficult to use and do not yet give the required support for the decision making. Moreover, five of the six interviewed medical doctors emphasised the importance of simple data visualisations for data interpretation. These could be for instance graphs, in comparison to detailed numerical data sets that patients may often bring to the doctor's appointment.

Likewise, one wellness expert mentioned that in training, both trainees and trainers benefit from simple data visualisations.

'Clearly interpreted and analysed data would help a personal trainer to plan the best approach for each individual. The personalised approach will help a person to be more motivated.' (Wellness service expert)

A wellness service expert has limited capability and also time available for interpreting customers' personal health and wellness data. Therefore, clear visualisations can help in data interpretation and in making a swift start to an actual training process.

The representatives of insurance companies regarded the use of an increasing amount of personal data on customers as generally positive. They, however, emphasised that the requirements for data vary between different user groups within the companies, and therefore, data presentation should be defined based on the needs of specific groups. For example, 
employees working with risk analysis data need different types of data presentations than employees working with customers.

A representative of a technology company thought that it is important for individuals to be continuously able to make a self-diagnosis and behaviour changes based on data. He admitted, though, that self-measurement is not necessarily easy:

'Methods of self-measurement must be as simple as possible for reaching all potential users. Simple visualisation is a must for an end-user.' (Director of a technology company)

Overall, all service providers considered clear visualisations based on data as an important enabler for utilising data. They, however, recognised that there is no single way to visualise data that would satisfy the needs and desires of all user groups. Instead, different user groups need various types of visualisations and levels of data presentation for decisionmaking purposes.

Some of the interviewed individuals specifically mentioned that it is not necessarily easy to interpret the medical data:

'I had an abnormal test result regarding insulin production. I did not notice it by myself ... The data could be presented better. I believe it could be done automatically.' (Male, 38 years old)

Lab tests in general produce a long list of numbers or reference values that people are not necessarily accustomed to reading. Data that is clearly presented, indicating noticeably normal vs. abnormal personal data within the range of given reference values, makes it easy for people to interpret their own data on a meaningful level.

\subsection{Actionability}

Actionability is based on the idea that data can serve as the basis for behaviour change [11]. Actionability appeared in the expectations of different service providers and individuals in many ways. Two of the interviewed medical doctors mentioned that a proactive way to collect personal health-related data (e.g. patient history and other data) helps doctors to focus discussions on relevant issues either an early phase or poststage of the treatments:

'We collect preliminary data through electronic surveys. The data from individuals helps us to focus the face-toface discussion on the right issues.' (Medical doctor in a health service provider)

Wellness training experts considered data-driven selfmonitoring as an important factor in the successful training process. According to them, systematic selfmonitoring is essential for supporting long-lasting change efforts in well-being. One interviewed wellness service expert admitted, though, that only some people become motivated to make behaviour changes based on specific personal health and wellness data while others need more personal support from, for instance, trainers:

'An important task of the wellness service expert is to give tools to a customer to take care of her/his wellbeing ... It helps the customer to take responsibility for his/her [own] well-being.' (Wellness service expert)

From the perspective of insurance companies, a great abundance of potentially useful data is available on individuals and their behaviour. This type of data could be useful, for instance, in preventing accidents.

'We could use sensors to see that there is something wrong with the wheel of the car if we know that a person has an intention to make a long trip with that car. It would be good to remind him/her to change the tyre.' (Director of an insurance company)

The representatives of insurance companies considered a proactive model emphasising individuals' wellness maintenance as an interesting business model. The monetary compensations for rewarding behaviour that advances health and wellness might act for some as a motivation for behaviour change. Currently, personal data is, however, strongly restricted by legal norms in the insurance business, which limits the possibilities for new business ideas in this area.

The representatives of technology companies emphasised that it is important to make people to think about their own well-being and initiate behaviour change instead of focusing too much on accuracy or optimising a single measurement. They, however, also admitted that measurements and data motivate only some people, while others are motivated by peer support, gamification or different reward systems, such as discounts on insurance payments.

'The most important thing is not to focus on accuracy or optimisation of a single measurement ... It is to get a person to think about his/her own well-being and take action.' (Director of a technology company)

Many interviewed individuals had high expectations that health data would increase their self-knowledge and thereby lead to behaviour change in a wide range of possible activities, such as physical exercise, sleep or eating. At least some people seemed to have high faith in the power of numbers for behaviour change. 
'[It is valuable] to gain knowledge about bad habits or behaviour that I could change; something that I might be aware of, but I could act on better when seeing it in the form of numbers.' (Male, 30 years old)

\subsection{Connection}

Connection means having a site for a conversation through data [11]. Data can then provide a structure and an opportunity for a conversation between individuals and professionals. In this study, the health professionals in private health organization felt that the personal data independently collected by the patient is an important starting point for discussions on medical care and helps to steer the discussion to healthy lifestyle.

'It would be important to see the sleep data and the [physical and mental] condition [of a person] as a baseline for discussion ... [We avoid] giving guidelines for lifestyle change to a person who has mental health problems.' (Nurse in a health service provider)

In public hospitals, four medical doctors evaluated the data as important baseline when discussing about the treatment discussions and reminding the patients of the needed actions.

"People should remember and to be reminded what to do e.g. when they are going to operation." (Medical Doctor in a public hospital)

Representatives of health service providers considered the data produced by various self-tracking devices as more reliable in comparison to the manually provided self-collected data as a basis for the dialog between individuals and health professionals. The wellness service providers emphasised that independently collected personal data is important not only as a starting point for customer relationships, but it also acts as a crucial driver for dialog throughout the training relationship.

One representative of an insurance company noted that customers do not necessarily have an understanding of insurance coverage just because they have read through the contract. This often leads to customer questions. In the resulting customer contacts, customer data serves as a valuable source and starting point for dialog. The insurance service providers also noted that customer data provides them with an opportunity to contact the customers in cases of potential problems with coverage and serve customer in a more personalised way.

'When a customer goes to get a treatment, doctors can't say whether the insurance will cover it.... We should see what the doctor sees, so that we would be able to tell customers [about their insurance coverage].' (Director of an insurance company)
Technology service providers suggested that the data from the health check-ups could be used to identify possible risk indicators and to generate ideas about the type of professionals that the technology user ought to talk with.

'It is a waste of time to talk to a doctor if the person actually needs a nutritional therapist.' (Director of a technology provider company)

Personal data could then help the individual to immediately find a relevant professional to talk with instead of visiting and having discussions with various professionals before finding the correct contact. The technology service providers also predicted that due to digitalisation, the dialog between the doctor and the patient will increasingly take place in the future virtually, i.e. through chat services instead of face-to-face discussions. Here, the pre-collected data could serve as an important starting point for mutual discussions and interpretations.

From the perspective of individuals, many saw their personal health data as the basis for discussions with experts on health and wellness. They mentioned that it would be useful to receive regular feedback on personal data, either to get support in data interpretation in general or for behaviour change in particular.

'I need help with the analysis of my personal data. Take, for example, my blood test results. ... The question still remains, what do these test results essentially say? What should I pay attention to? ... There is a need for professional interpretation.' (Female, 42 years old)

\subsection{Transparency}

Transparency refers to the accessibility of data across different cases or contexts [11]. It considers the possibilities of individuals, for example, to share their data across clinical and nonclinical contexts. Transparency is also related to individuals' access to their own data, e.g. data that is collected into the electronic medical records. The analysis suggests that nowadays, people may bring a great deal of different personal data to their appointments with representatives of various service providers. In the past, people used to only describe their symptoms to healthcare and wellness professionals orally, but today many people can go to these meetings with excel sheets showing data that has been collected via, for instance, self-tracking devices.

'The more people share their data, the more they can be helped and guided by the healthcare professionals.' (Nurse in a health service provider) 
Both health and wellness service providers mentioned that the trend towards better data transparency and data access will help them offer better and more focused services. In fact, the transparency of patient data was revealed to be important in five of the analysed medical doctor interviews:

'It is important that the care and care process is transparent for the patients.' (Medical doctor in a public hospital)

However, they cautioned that sensitive data may exist that should not necessarily be shown to the individuals at all. Two of the interviewed medical doctors also highlighted that patients' health data cannot be shared with external (non-clinical) actors, as the use of patient data is strictly regulated.

"The data sharing should be solved safe according to the regulations." (Medical doctor in a public hospital)

Wellness providers mentioned that sometimes, the medical condition of a person can cause a situation where the lack of data transparency may even pose a life-threatening risk to the person in the training programme.

'Once, there was a customer who forgot to tell us about his heart medication. He participated in the training group, doing heavy exercises, and wondered why he felt so ill in the middle of the exercise.' (Wellness service expert)

The representatives of insurance service providers talked about data transparency with some reservation. According to one insurance company representative, the sharing of data requires safe and standardised way to transfer and store information. He noted that a reserved attitude among individuals towards insurance companies may limit individuals' willingness to share their personal data and that insurance companies must communicate to customers carefully how their data will be utilised.

'The insurance business is so tightly regulated that we have to be alert every time when a new data protection regulation takes effect.' (Director of an insurance company)

Another representative of an insurance company highlighted the traditional view on personal data, which considers the possibilities for sharing and utilising data between different business contexts as being limited. This perspective emphasises the careful protection of company data. He noted that changes in attitudes towards open innovation thinking are slow.
One representative of a technology service provider mentioned that due to more cost-effective sensor solutions in devices, there will be more and more data in the future. At the same time, there seems to be a trend that people nowadays provide access to their personal data more readily to different service providers in the health and wellness ecosystem. This means that companies may need to rethink their business strategies regarding utilisation of personal data.

'Even though many organisations are excited about the possibility to take advantage of customers' personal data, there are also many companies that consider data transparency as posing a threat to their businesses.' (Manager of a technology company)

One representative of a technology company viewed that there is a clear line between health and wellness data, making the point that companies must be careful that these different types of data sets are not mixed in their service offerings due to different regulatory requirements for managing personal health and wellness data. Offences against data regulations may pose a serious risk for the business.

The interviewed individuals emphasised the importance of gaining easy access to their own medical records. In this respect, many interviewees mentioned that it would be particularly important to be able to gain quick access to one's existing records on vaccinations.

'Healthcare professionals need to gain access to my data regardless of whether I am a customer in the public or private sector. ... I need to gain access digitally to my own data in case I need to find out about my own medical records.' (Female, 45 years old)

\subsection{Truthiness}

The truthiness of data refers not only to the validity of the data, but also to the sense of truth ascribed to the data. This data valence considers quantitative data to be 'truer' than other types of data [11]. From the perspective of both health and wellness service providers, the challenge is that people do not necessarily want or remember to provide all relevant information about themselves to help the doctor or coach make a diagnosis and offer the right kinds of treatments or pieces of advice:

'As a doctor, I always consider the data with some reservation. If I ask you how much alcohol you drink, most likely the answer that I get has to be multiplied before I get the right amount. The same applies with the weight issue. If I ask about [body] weight, people usually report 
[weighing] one or two kilos less than what is accurate.' (Medical doctor in a health service provider)

'... of course [it is beneficial], so that it [data] is already collected and it is automatic, so you don't have to rely only on what a customer remembers or wants to tell.' (Wellness service expert)

Building trust is, therefore, essential for gaining accurate data. However, building trust with an individual can be difficult without face-to-face communication.

One solution for the problem of data accuracy is automated data collection using reliable medical devices and digital platforms. In these cases, the validity of the data is not dependent on the person, but on the reliability of the measurement devices and technology infrastructures. Questions related to the truthiness of data also emerged in the comments made by insurance company representatives. One insurance company representative wondered how long the collected data from an individual will actually remain valid. Thus, time is also an important aspect to take into account when suggesting treatments or giving advice to a person. In the insurance business, premiums and insurance pay-outs are often based on customer reports. The availability of additional personal data on customers could help companies gain more exact information on a customer's particular circumstances. One representative of an insurance company thought that richer and more exact health- and wellnessrelated data might also provide a fairer distribution of the costs among different customer groups:

'A customer can get a feeling regarding [what is] fair treatment ... if $\mathrm{s}(\mathrm{he})$ does not have to pay for the ear infections of neighbours.' (Director of an insurance company)

Technology providers noted that the key problem regarding the truthiness of data is that there are still only a few technological interfaces between different service providers and that true collaboration does not necessarily take place between the existing companies:

'If you give recommendations for some treatment, the [health] data must be correct.' (Manager of a technology company)

Additionally, the devices that collect the health or wellness data are often not certified. Therefore, there is no guarantee that the information they collect is correct or that they can be used for making absolutely accurate interpretations of a person's health. One technology service provider added, though, that in the field of wellness it can sometimes be more important to get a person to change her/his lifestyle than to accurately interpret the data.
Regarding the truthiness of data, many of the interviewed individuals gave their perspectives particularly on selftracking data. For them, the relationship to their self-tracking data seems to be generally twofold. On the one hand, they hope to gain accurate data. At the same time, however, they recognise that some of their activities remain unmeasured.

'The device does not always recognise my [type of] activities. Whether it is walking or running. ... It does not bother me, as I believe that the data is approximately what it ought to be (say, measured in a thousand steps).' (Female, 45 years old)

\subsection{Discovery}

Discovery means that the data is used as a baseline for making a hypothesis or discovering new knowledge. As an example, at the individual level discovery valence can be related to the need to identify a correlation between, say, coffee consumption and blood pressure [11]. In this study, health service providers were excited about the possible discoveries that they could make based on the data that individuals gain through self-measurement at home:

'For example, blood pressure and blood sugar measurements are much more reliable if they are made at home. Asthma patients may come to the appointment with data that they have collected at home for two weeks.' (Medical doctor in a health service provider)

For the interviewed medical doctors, the increasing amount of data based on monitoring at home gives new possibilities to check, for instance, the development of chronic diseases, the contributing factors and impact of the treatments. It was reminded, however, by the interviewed medical doctors that the data cannot be the only baseline for the decisions and discussions. Often, medical doctors also use intuition for decision making that can be difficult to be replaced by the machine based analysis.

Wellness providers commented that some people get highly motivated when they understand their health problem, for instance through blood test results:

'Half of the people having type II diabetes are not aware of it. That is terrifying. Therefore, systematic ways to examine risk profiles and to make discoveries about [a person's own] health situation would be really important.' (Wellness service expert)

Visible data may help people to make concrete lifestyle changes. People may continue monitoring their health status for a 
longer period of time and learn that their own actions can have an effect on their health.

Insurance company representatives reported that they are quite interested in discovering the risk factors for accidents and chronic diseases. Companies have already started to make their data available to technology developers, who can calculate the correlations between the risk and accident profiles. This means that with richer data, insurance companies can better test, validate and develop their risk and accident portfolios.

The technology service providers said that it is important to give people some understanding of their health status and its development through certain key indicators. This means that technology providers aim to motivate people to make lifestyle changes through the numbers provided by the devices. One representative of a technology company developing wellness and training applications emphasised the need to support training through constant and long-term monitoring of the progress and effects of the training programme.

The interviews with individuals revealed that some people hope to gain insights into their own behaviour through pattern recognition in long-term data sets. Short experiments might provide insights into people's existing behaviour.

'I kept a food diary for only about three weeks. It was enough for me to see roughly how I eat. I had no intentions to keep it for a long period of time.' (Female, 40 years old)

\subsection{Summary of the results}

Table 2 summarises the results of the analysis based on the data valence typology defined by [11]. The left column in Table 2 presents the interviewed participants in the personal data-driven health and wellness service ecosystem of the study, while the top row presents the data valences analysed in the study.

\section{Discussion}

This study has analysed the data valences i.e. different expectations of various private sector service providers and individuals regarding personal health and wellness data. Knowledge on such expectations is essential to increase understanding on the premises of an emerging service ecosystem based on personal data around proactive health and wellness maintenance. Regarding self-evidence, both service providers and individuals emphasised that clear data presentations and visualisations are crucial when utilising personal health and wellness data. This finding is in line with the study by [20], who identified the ability to make sense of data as an essential factor in utilising patient-generated data from the perspective of patients. Similarly, Schroeder et al. [29] highlighted the importance of simple and understandable data presentations. The possibility for incorrect self-diagnosis has been identified as a risk (see, e.g. [11, 64]). Raj et al. [30] have highlighted the role of different types of visualisations to draw insights from health data. The findings of this study regarding self-evidence go even further as the results stress the importance of providing different user groups with a customised presentation of data that is based on the needs of each user group.

Regarding actionability, the results stress the importance of motivational aspects in making behaviour and lifestyle changes. The service providers underscored the importance of collecting, analysing and sharing personal data that may affect individual motivation. As suggested by Fiore-Gartland and Neff [11], the various aspects of the data, knowledge and action are all crucial elements in actionability. Earlier research by Chung et al. [26] found that self-monitoring data both motivates and educates patients. For individuals, knowledge about the status of their personal health may lead to behaviour change. The health and wellness service providers noted that the availability of data could well support them in offering more personalised services. This finding is related to a more personalised healthcare and wellness trend, from which the platform for person-centric health and wellness support (see [32]) is a good example. All the interviewed stakeholders seem to highlight that data helps to motivate people for changing their health behaviour. However, achieving permanent impacts for healthy behavior through continuous data flows can be more challenging. Many users of wearables, for example, abandon their devices after a relatively short period after the adoption [65]. Personalization of data is one potential area that may support long-term relationship between individuals, wearable technologies, and the data they produce [31].

Earlier studies have shown that the interpersonal dynamics between health providers and individuals can influence an individual's wellbeing [66]. Data can act here as an important intermediary or a space for connection [11]. This study found that service providers and individuals expect data in particular to act as a basis for personalising information and creating better dialog between individuals and service providers. Healthcare and wellness professionals in particular considered privately collected personal data to represent an important starting point for discussions. This supports the suggestion that data can serve as a site for generating conversation [11]. Additionally, data was identified here as a support element for face-to-face discussions as well as conversing by telephone or online. Similarly, Chung et al. [26] and Chung [40] suggest that self-monitoring data will enhance communication between patients and health service providers. Findings of this study are also in line with Kim et al. [39], who suggest that data-driven consultation supports more in-depth conversations between the patient and the provider. The technology 
Table 2 Role-specific findings of the personal data-driven health and wellness service ecosystem

\begin{tabular}{|c|c|c|c|c|c|c|}
\hline $\begin{array}{l}\text { Role } \\
\text { (interviewees)/ } \\
\text { Data valence }\end{array}$ & Self-evidence & Actionability & Connection & Transparency & Truthiness & Discovery \\
\hline $\begin{array}{l}\text { Health service } \\
\text { provider } \\
1 \text { private } \\
\text { medical } \\
\text { centre } \\
2 \text { public } \\
\text { hospitals } \\
8 \text { interviewees } \\
7 \text { interview } \\
\text { sessions }\end{array}$ & $\begin{array}{l}\text { - Clear } \\
\text { visualisations } \\
\text { - People can get } \\
\text { lost with } \\
\text { personal data }\end{array}$ & $\begin{array}{l}\text { - Taking action on } \\
\text { relevant things } \\
\text { at an early phase } \\
\text { - Varying needs } \\
\text { and } \\
\text { motivational } \\
\text { aspects behind } \\
\text { behaviour }\end{array}$ & $\begin{array}{l}\text { - Independently collected } \\
\text { personal data as a starting } \\
\text { point for medical care }\end{array}$ & $\begin{array}{l}\text { - The more people } \\
\text { are sharing } \\
\text { personal data, the } \\
\text { more they can be } \\
\text { helped } \\
\text { - Medical data cannot be } \\
\text { shared without } \\
\text { limitations }\end{array}$ & $\begin{array}{l}\text { - Truthfulness of } \\
\text { people's } \\
\text { narratives vs. } \\
\text { measured data }\end{array}$ & $\begin{array}{l}\text { Self-measurem } \\
\text { ent at home for } \\
\text { identifying fac- } \\
\text { tors behind the } \\
\text { disease }\end{array}$ \\
\hline $\begin{array}{l}\text { Wellness } \\
\quad \text { service } \\
\text { provider } \\
2 \text { wellness } \\
\quad \text { companies } \\
4 \text { interviewees } \\
2 \text { interview } \\
\quad \text { sessions }\end{array}$ & $\begin{array}{l}\text { - Clear } \\
\text { visualisations } \\
\text { - User } \\
\text { group-specific } \\
\text { data presenta- } \\
\text { tions }\end{array}$ & $\begin{array}{l}\text { - Self-monitor- } \\
\text { ing for } \\
\text { supporting } \\
\text { behaviour } \\
\text { change } \\
\text { - Varying needs } \\
\text { and } \\
\text { motivational } \\
\text { aspects } \\
\text { behind } \\
\text { behaviour }\end{array}$ & $\begin{array}{l}\text { - Independently collected } \\
\text { personal data as a driver } \\
\text { for detailed discussions }\end{array}$ & $\begin{array}{l}\text { - Using health data } \\
\text { (medical history data) } \\
\text { for a risk analysis } \\
\text { regarding training }\end{array}$ & $\begin{array}{l}\text { - Truthfulness of } \\
\text { people's } \\
\text { narratives vs. } \\
\text { measured } \\
\text { data }\end{array}$ & $\begin{array}{l}\text { - Self-monitoring } \\
\text { for verifying } \\
\text { effects of train- } \\
\text { ing }\end{array}$ \\
\hline $\begin{array}{l}\text { Insurance } \\
\text { service } \\
\text { provider } \\
2 \text { insurance } \\
\text { companies } \\
4 \text { interviewees } \\
3 \text { interview } \\
\text { sessions }\end{array}$ & $\begin{array}{l}\text { - Data } \\
\text { presentations } \\
\text { based on } \\
\text { targets } \\
\text { of use }\end{array}$ & $\begin{array}{l}\text { - Compensation } \\
\text { based on } \\
\text { personal data } \\
\text { - Varying } \\
\text { motivational } \\
\text { aspects behind } \\
\text { behaviour }\end{array}$ & $\begin{array}{l}\text { - Data as a source for dialog } \\
\text { with customers }\end{array}$ & $\begin{array}{l}\text { - People's reserved } \\
\text { attitudes } \\
\text { - Conservative } \\
\text { thinking about } \\
\text { sharing data with } \\
\text { companies }\end{array}$ & $\begin{array}{l}\text { - More tailored } \\
\text { service } \\
\text { through } \\
\text { more exact } \\
\text { and richer } \\
\text { data }\end{array}$ & $\begin{array}{l}\text { - Finding links in } \\
\text { the data for } \\
\text { understanding } \\
\text { the risks }\end{array}$ \\
\hline $\begin{array}{l}\text { Technology } \\
\text { service } \\
\text { provider } \\
4 \text { technology } \\
\text { companies } \\
4 \text { interviewees } \\
4 \text { interview } \\
\text { sessions }\end{array}$ & $\begin{array}{l}\text { - Simple } \\
\text { visualisations } \\
\text { of the overall } \\
\text { situation } \\
\text { - Varying } \\
\text { visualisation } \\
\text { needs for } \\
\text { different } \\
\text { user groups }\end{array}$ & $\begin{array}{l}\text { - Varying } \\
\text { motivational } \\
\text { aspects } \\
\text { - Waking up the } \\
\text { customer }\end{array}$ & $\begin{array}{l}\text { - Avoiding unnecessary } \\
\text { discussions by } \\
\text { connecting customers } \\
\text { with relevant } \\
\text { professionals } \\
\text { - Pre-collected personal da- } \\
\text { ta as } \\
\text { a starting point in virtual } \\
\text { health services }\end{array}$ & $\begin{array}{l}\text { - Conservative } \\
\text { thinking about } \\
\text { sharing data with } \\
\text { companies } \\
\text { - Line between health } \\
\text { and wellness data }\end{array}$ & $\begin{array}{l}\text { - Need for } \\
\text { certified } \\
\text { solutions } \\
\text { - Accuracy of } \\
\text { personal data }\end{array}$ & $\begin{array}{l}\text { - Self-monitoring } \\
\text { for verifying } \\
\text { effects of train- } \\
\text { ing }\end{array}$ \\
\hline $\begin{array}{l}\text { Individual } \\
\text { Interviews in } 2 \\
\text { phases } \\
\text { 1st phase: } \\
27 \\
\text { inter- } \\
\text { viewees } \\
27 \text { interview } \\
\text { sessions } \\
2 \text { nd phase: } \\
21 \\
\text { inter- } \\
\text { viewees } \\
21 \\
\text { interview } \\
\text { sessions }\end{array}$ & $\begin{array}{l}\text { - Clear } \\
\text { presentation } \\
\text { on health data } \\
\text { indicating } \\
\text { normal } \\
\text { vs. abnormal } \\
\text { results }\end{array}$ & $\begin{array}{l}\text { - Self-knowle- } \\
\text { dge through } \\
\text { data } \\
\text { - Behaviour } \\
\text { change through } \\
\text { data }\end{array}$ & $\begin{array}{l}\text { - Personal data as a basis for } \\
\text { face-to-face discussions } \\
\text { with and regular feed- } \\
\text { back from } \\
\text { experts on health and } \\
\text { wellness }\end{array}$ & $\begin{array}{l}\text { - Accessibility to } \\
\text { own health data } \\
\text { - Accessibility to } \\
\text { person's medical } \\
\text { data by necessary } \\
\text { healthcare } \\
\text { organisations }\end{array}$ & - Data accuracy & $\begin{array}{l}\text { - Pattern } \\
\text { recognition in } \\
\text { long-term data } \\
\text { sets } \\
\text { - Short } \\
\text { experiments } \\
\text { lasting a few } \\
\text { weeks }\end{array}$ \\
\hline
\end{tabular}

service provider in this study highlighted the increasing importance of person-generated data in the future due to the emerging amount of virtual health check-ups. Patient portals
[37] and the increasing interest of using patient generated health data [38] can be seen as a foundation for a more dynamic communication between customers/patients and 
service providers. This study suggests, however, that it is necessary to be sensitive and recognize the context of the data when having conversations initiated by person-generated data as otherwise, it can be challenging to make appropriate interpretations based on data. It seems then that connection valence is closely connected with the self-evidence valence that highlights the importance of the clear visualisations of data.

Even though many interviewees in this study considered open data sharing in general as positive, transparency proved to be the dimension that revealed most of the differences regarding expectations. Healthcare providers noted that it might be problematic, even dangerous, to give an individual access to all of his/her data. This is because people do not necessarily have adequate competence to interpret data properly, which can lead to risky actions in terms of health. Wellness service experts claimed that for them, the availability of medical data would help them decrease sometimes even life-threatening risks in training programmes. Currently, it is illegal for wellness service experts to use medical data. Similar to the findings presented by $[42,45,67,68]$, this study found that individuals consider it important to have access to and control of their own data. Insurance and technology service providers underlined the fact that current thinking on the sharing of data between companies is still conservative and that data is often seen as a value asset that must be protected by a company. Data transparency can thus be seen businesswise as a complex thing for many companies as it is difficult to identify the value that can either be achieved or lost by sharing data assets managed by the company. In addition, the results show that individuals hesitate for sharing their data with insurance companies. This finding is line with the previous study by Grundstrom \& Karampela [47], who suggest that transparency and trust building are important for motivating customers to share their health data with insurance companies. Additionally, technology service providers emphasised that they have strictly separated services using either health- or wellness-related personal data due to regulations. The need for clear legal standards for the use of person generated health data in a clinical context has also been noted earlier (e.g. [46]).

Truthiness of data was also highlighted in the collected data. The service providers in this study emphasised that any documented personal data, collected by, e.g. self-tracking tools, is more reliable than the narratives that people tell about their behaviour. This notion was particularly highlighted by health and wellness professionals, who work directly with patients or customers. Individuals themselves and technology service providers, however, emphasised the fact that data accuracy is the single biggest problem when it comes to reliable data usage. Earlier research have found that current tools for collecting personal data have variation in data accuracy [50]. This aspect is important to take into account when assessing the truthiness of data. The technology service provider highlighted the need for certified personal data tracking solutions for achieving more reliable and accurate data. Similarly, Chung et al. [26] underlined the need for selfmonitoring tools with standardised formats and workable data sharing capabilities. Additionally, the ability to identify the origins of data, e.g. patients or health records, is critical for creating trust with respect to the data [27]. Importantly, this study also raised the question of the temporal dimension regarding the validity of data. This aspect was reflected, for instance, by the interviewed representative of the insurance company. Therefore, this study suggests that in addition to context, the requirements for personal data updates should also be always investigated carefully when assessing truthiness of data.

Discovery related aspects were also mentioned by different stakeholders. Though various service providers in the study considered personal data as an asset that could be used to produce new knowledge, they expressed different reasons for such expectations. Both health and insurance providers expected that data could help them identify risk indicators. The health providers said that people's self-tracking data could help reveal, for instance, the risk factors behind chronic diseases. Insurance service providers stated that better utilisation of rich data could also help them discover the risk factors for accidents. Wellness service providers noted that data could help them with training. Data can act as a motivation and source of verification for individuals regarding the need for behaviour change. Individuals, again, considered the long-term documentation of health- and wellness-related data as a way for them to increase their self-knowledge. This is in line with existing studies that have noted that information helps people in decision-making regarding behaviour change (e.g. [68]). The findings also support the results of Mamykina et al. [52], who suggest that discovering patterns regarding individual's activities and changes, for instance, in blood glucose levels using self-monitoring data can enhance selfmanagement of chronic diseases.

Overall, the study revealed that both individuals and healthcare service providers emphasize expectations on clear data presentation and visualization. Otherwise there is a risk for incorrect diagnostics. The study also suggests that in the future data can act as a basis for information personalization which may support dialog between individuals and service providers. The results show that the different ecosystem actors have different expectations regarding to health and wellness data potential. In the future, data could be used, for example, to better identify risk indicators behind chronic diseases, risk indicators for accidents or as a basis for more personalised personal training services. The time and context of data production are, however, important aspects to consider when utilizing data in service ecosystem.

The study offers several considerations based on different expectations of service providers and individuals to personal data. First, there is a need to visualise the data in a way that it 
can be easily interpreted. Additionally, the study suggests that professional or experienced and non-experienced users of data need different types of data visualisations and presentations. This requires flexibility and the configuration of information systems in a way that they produce and present multi-source data to different actors related to the personal data usage. Second, motivation to change health behaviour is a complex issue. Different things can motivate different people. The study suggests that it is important for service providers to identify whether multi-source data motivates different groups of people and what kinds of services support this finding. Here, previous research on motivation can provide valuable insights for identifying motivational aspects for the future health and wellness services. Third, expectations for data accuracy vary between participants and contexts. As an example, in the first meeting with a patient a medical doctor can be satisfied even with rough patient-generated data if it supports the narrative of the patient. The study suggests that the requirements for data accuracy ought to be aligned with the expectations of different ecosystem members. Fourth, data transparency is the key factor in the personal data service creation. The conservative approach to customer-related data as an internal value asset of a company can limit or even prevent the development of the personal data-driven services. Therefore, it is important that participants related to the personal data flow identify what kind of value they gain from and give to the individuals. Additionally, a technical infrastructure for sharing data and integrating multi-source personal data is essential for the development of the services. Here, different regulatory requirements for managing personal health and wellness data form a necessary foundation.

There are several avenues for future studies. Future research regarding personal data-driven service ecosystems ought to explore the platform ecosystem perspective, highlighting the role of data as a boundary resource between different service providers [69]. It would be important to examine how data is utilised, shared and re-used to create future healthcare services. From a practical standpoint, viewing data as a dynamic resource in the service ecosystem requires that the involved organisations consider personal data from different perspectives for co-creating value. Future research could therefore study the use of data as a dynamic capability [70, 71]. Future research could also focus on examining the value co-creation practices and processes in the service ecosystem, and how these are reflected when ecosystems reach a more mature level. Currently, various healthcare services utilise data from a wide range of sources [22], and resources from different areas of the healthcare sector bring out the concept of collaborative service creation in ecosystems, which can be referred to as service ecosystems. In the future studies it would be interesting to approach the data expectations from the perspective of service ecosystems based on the definitions rooted in service-dominant logic (SDL) [72, 73].
The major limitations of this study are related to the sample regarding data collection. Twenty professionals were interviewed for collecting qualitative data. Interviewees represented different types of organisations, which are interested in using personal health and wellness data in their businesses. For example, a clinical healthcare perspective was represented by one large private medical centre and two public hospitals, from which six medical doctors and two nurses participated in interviews. Even though interviewed persons were experienced professionals, a larger group of healthcare professionals would strengthen and broaden the highly important aspects of clinical healthcare professionals in the context of emerging personal data-driven ecosystems. Additionally, it is important to notice that all interviews were conducted only in one country, Finland. In future studies the understanding of expectations of different business actors should be deepened by collecting more data from relevant firms and organisations in different countries. This would broaden our understanding and possibly produce more generalizable results of this complex phenomenon in and across different cultural contexts.

\section{Conclusions}

Healthcare service providers are seen as 'high-reliability organisations' [74], which means that healthcare providers need to rely on complex interactions with various stakeholders, yet they also need to make decisions in a highly dynamic and unpredictable environment. At the same time, the sharing and re-using of personal data among those stakeholders contains challenges with respect to business use [75]. This study argues that when creating personal data-driven services, it is particularly important to pay careful attention to questions such as data presentations, the motivational aspects of data, the transparency of data, as well as the accuracy of data.

Based on the results of this study it can be concluded that emerging health data driven service ecosystems have a potential to promote the change in the field of healthcare services and support for achieving a proactive service model. Even though there are varying expectations to personal health data and also some concerns, it can be seen that here different ecosystem actors primarily perceived the wider use of personal health and wellness data as a positive trend. The emerging health data driven service ecosystem promotes practical implications that are relevant in particular to the creation of proactive collaborative health services. One factor contributing to the increasingly active role of people themselves in healthcare settings is the development of different kinds of technological solutions around personal data, such as home-measurement devices or self-tracking and activity-level wearables. All of these technologies offer novel possibilities to utilise healthand wellness-related personal data in the development of proactive predictive, preventive, participatory and personalised 
healthcare services [8]. Importantly, however, the emphasis on technologies may come at the expense of other essential aspects, such as organisation and communication in digitisation of healthcare [76].

In general, it can be seen that a starting point for the change towards more collaborative personal health data-data driven service ecosystems that supports a proactive healthcare service model is promising. However, the change towards health data-driven service ecosystems requires more openness from all stakeholders and often transformation in the company's mindset concerning the traditional view of utilisation and ownership of data. A fundamental requirement for achieving potential benefits from different types of personal health data is that value can be clearly provided for all actors in the service ecosystem.

Acknowledgements Open access funding provided by Technical Research Centre of Finland (VTT). We would like to thank the organizer of the 'Digital Health Revolution' (DHR) health and wellness pilot initiative, the Institute for Molecular Medicine Finland (FIMM), HiLIFE, the University of Helsinki and particularly Riitta Sallinen \& Anu Karhu for all their help and collaboration. In addition, we would like to thank all the interviewees who participated in this study. The comments and suggestions by the editor and two anonymous reviewers are also gratefully acknowledged.

Funding information The research was supported by a grant from Tekes - the Finnish Funding Agency for Innovation - as part of the Digital Health Revolution programme. The multi-disciplinary programme was coordinated and managed by the Centre for Health and Technology, University of Oulu, Finland.

\section{Compliance with ethical standards}

Conflict of interest The authors declare that they have no conflict of interest.

Ethical approval The DHR Pilot Study was conducted according to the guidelines of the Declaration of Helsinki. The study protocol was approved by the Coordinating Ethics Committee of the HUS Hospital District (51/13/03/00/15). In addition, this study was conducted according to the ethical principles of research in the humanities and social and behavioural sciences of the University of Helsinki.

Informed consent Informed consent was obtained from all individual participants included in the study.

Open Access This article is licensed under a Creative Commons Attribution 4.0 International License, which permits use, sharing, adaptation, distribution and reproduction in any medium or format, as long as you give appropriate credit to the original author(s) and the source, provide a link to the Creative Commons licence, and indicate if changes were made. The images or other third party material in this article are included in the article's Creative Commons licence, unless indicated otherwise in a credit line to the material. If material is not included in the article's Creative Commons licence and your intended use is not permitted by statutory regulation or exceeds the permitted use, you will need to obtain permission directly from the copyright holder. To view a copy of this licence, visit http://creativecommons.org/licenses/by/4.0/.

\section{References}

1. Hood L. Health care of the 21st century: predictive, preventive, personalized and participatory (P4) medicine. J Oral Maxillofac Surg. 2006;64(9):14.

2. Cline JS. The promise of data-driven care. N C Med J. 2014;75(3): $178-82$.

3. Sharon T. Self-tracking for health and the quantified self: rearticulating autonomy, solidarity, and authenticity in an age of personalized healthcare. Philos Technol. 2017;30(1):93-121.

4. Carver CS, Scheier MF. On the self-regulation of behavior. New York: Cambridge University Press; 1998.

5. Pikkarainen M, Pekkarinen S, Koivumäki T, Huhtala T. Data as a driver for shaping the practices of a preventive healthcare service delivery network. J Innov Manag. 2018;6(1):55-79.

6. Xie K, Wu Y, Xiao J, Hu Q. Value co-creation between firms and customers: the role of big data-based cooperative assets. Inf Manag. 2016;53(8):1034-48.

7. Hood L. Systems biology and p4 medicine: past, present, and future. Rambam Maimonides Med J. 2013;4(2)1-15.

8. Flores M, Glusman G, Brogaard K, Price ND, Hood L. P4 medicine: how systems medicine will transform the healthcare sector and society. Pers Med. 2013;10(6):565-76.

9. Swan M. Emerging patient-driven health care models: an examination of health social networks, consumer personalized medicine and quantified self-tracking. Int J Environ Res Public Health. 2009;6(2): 492-525.

10. Kindström D, Kowalkowski C, Sandberg E. Enabling service innovation: a dynamic capabilities approach. J Bus Res. 2013;66(8): 1063-73.

11. Fiore-Gartland B, Neff G. Communication, mediation, and the expectations of data: data valences across health and wellness communities. Int J Commun. 2015;9:19.

12. Reading MJ, Merrill JA. Converging and diverging needs between patients and providers who are collecting and using patientgenerated health data: an integrative review. J Am Med Inform Assoc. 2018;25(6):759-71.

13. Patterson H, Nissenbaum H. Context-dependent expectations of privacy in self-generated mobile health data. Available at SSRN 3115768. 2013 May 22.

14. Bagot M, Launay P, Guidec F. Toward an open-source flexible system for Mobile health monitoring. In international conference on wireless mobile communication and healthcare 2016 Nov 14. Cham: Springer. p. 79-82.

15. Choe EK, Lee NB, Lee B, Pratt W, Kientz JA. Understanding quantified-selfers' practices in collecting and exploring personal data. In Proceedings of the SIGCHI Conference on Human Factors in Computing Systems 2014 Apr 26 (pp. 1143-1152). ACM.

16. Koivumäki T, Pekkarinen S, Lappi M, Väisänen J, Juntunen J, Pikkarainen M. Consumer adoption of future MyData-based preventive eHealth services: an acceptance model and survey study. J Med Internet Res. 2017;19(12):e429.

17. Frost J, Massagli M. Social uses of personal health information within PatientsLikeMe, an online patient community: what can happen when patients have access to one another's data. J Med Internet Res. 2008;10(3):e15.

18. Wilkowska W, Ziefle M. Privacy and data security in E-health: requirements from the user's perspective. Health Inform J. 2012;18(3):191-201.

19. Vargo SL, Wieland H, Akaka MA. Innovation through institutionalization: a service ecosystems perspective. Ind Mark Manag. 2015;44:63-72.

20. Chung CF, Dew K, Cole A, Zia J, Fogarty J, Kientz JA, Munson SA. Boundary negotiating artifacts in personal informatics: patient- 
provider collaboration with patient-generated data. InProceedings of the 19th ACM Conference on Computer-Supported Cooperative Work \& Social Computing 2016 Feb 27 (pp. 770-786). ACM.

21. Grossman JM, Zayas-Cabán T, Kemper N. Information gap: can health insurer personal health records meet patients' and physicians' needs? Health Aff. 2009;28(2):377-89.

22. Wang Y, Hajli N. Exploring the path to big data analytics success in healthcare. J Bus Res. 2017;70:287-99.

23. Iivari M, Pikkarainen M, Koivumäki T. How MyData is transforming the business models for health insurance companies. In working Conference on Virtual Enterprises 2017 Sep 18 (pp. 323-332). Springer, Cham.

24. Rohm AJ, Milne GR. Just what the doctor ordered: the role of information sensitivity and trust in reducing medical information privacy concern. J Bus Res. 2004;57(9):1000-11.

25. Shapiro M, Johnston D, Wald J, Mon D. Patient-generated health data. RTI International, April. 2012 Apr.

26. Chung CF, Cook J, Bales E, Zia J, Munson SA. More than telemonitoring: health provider use and nonuse of life-log data in irritable bowel syndrome and weight management. J Med Internet Res. 2015;17(8):e203.

27. Deering MJ. Issue brief: patient-generated health data and health IT. Office of the National Coordinator for Health Information Technology. Washington, DC: U.S. Department of Health and Human Services. December 2013.

28. Mentis HM, Komlodi A, Schrader K, Phipps M, Gruber-Baldini A, Yarbrough K, Shulman L. Crafting a view of self-tracking data in the clinical visit. In Proceedings of the 2017 CHI Conference on Human Factors in Computing Systems 2017 May 2 (pp. 58005812). ACM.

29. Schroeder J, Hoffswell J, Chung CF, Fogarty J, Munson S, Zia J. Supporting patient-provider collaboration to identify individual triggers using food and symptom journals. InProceedings of the 2017 ACM Conference on Computer Supported Cooperative Work and Social Computing 2017 Feb 25 (pp. 1726-1739). ACM.

30. Raj S, Newman MW, Lee JM, Ackerman MS. Understanding Individual and Collaborative Problem-Solving with PatientGenerated Data: Challenges and Opportunities. Proceedings of the ACM on Human-Computer Interaction. 2017 Dec 6;1(CSCW):88.

31. Hänsel K, Wilde N, Haddadi H, Alomainy A. Wearable computing for health and fitness: exploring the relationship between data and human behaviour. arXiv preprint arXiv:1509.05238. 2015 Sep 17.

32. Banos O, Amin MB, Khan WA, Afzel M, Ahmad M, Ali M, Ali T, Ali R, Bilal M, Han M, Hussain J. An innovative platform for person-centric health and wellness support. In International Conference on Bioinformatics and Biomedical Engineering 2015 Apr 15 (pp. 131-140). Springer, Cham.

33. Hänsel K, Wilde N, Haddadi H, Alomainy A. Challenges with current wearable technology in monitoring health data and providing positive behavioural support. In Proceedings of the 5th EAI International Conference on Wireless Mobile Communication and Healthcare 2015 Dec 22 (pp. 158-161). ICST (Institute for Computer Sciences, Social-Informatics and Telecommunications Engineering).

34. Miyamoto SW, Henderson S, Young HM, Pande A, Han JJ. Tracking health data is not enough: a qualitative exploration of the role of healthcare partnerships and mHealth technology to promote physical activity and to sustain behavior change. JMIR mHealth uHealth. 2016;4(1):e5.

35. Baumer EP. Reflective informatics: conceptual dimensions for designing technologies of reflection. In Proceedings of the 33rd Annual ACM Conference on Human Factors in Computing Systems 2015 Apr 18 (pp. 585-594). ACM.
36. Kocielnik R, Hsieh G, Avrahami D. Helping users reflect on their own health-related behaviors. InStudies in conversational UX design 2018. Cham: Springer. p. 85-115.

37. Wells S, Rozenblum R, Park A, Dunn M, Bates DW. Personal health records for patients with chronic disease. Appl Clin Inform. 2014;5(02):416-29.

38. Lai AM, Hsueh PY, Choi YK, Austin RR. Present and future trends in consumer health informatics and patient-generated health data. Yearb Med Inform. 2017;26(01):152-9.

39. Kim Y, Heo E, Lee H, Ji S, Choi J, Kim JW, Lee J, Yoo S. Prescribing 10,000 steps like aspirin: designing a novel interface for data-driven medical consultations. In Proceedings of the 2017 CHI Conference on Human Factors in Computing Systems 2017 May 2 (pp. 5787-5799). ACM.

40. Chung CF. Using personal informatics data in collaboration among people with different expertise (Doctoral dissertation); 2018.

41. Sands DZ, Wald JS. Transforming health care delivery through consumer engagement, health data transparency, and patientgenerated health information. Yearb Med Inform. 2014;23(01): $170-6$.

42. Kish LJ, Topol EJ. Unpatients - why patients should own their medical data. Nat Biotechnol. 2015;33(9):921.

43. Kostkova P, Brewer H, de Lusignan S, Fottrell E, Goldacre B, Hart $\mathrm{G}$, et al. Who owns the data? Open data for healthcare. Front Public Health. 2016;4:7.

44. Nohr C, Wong MC, Turner P, Almond H, Parv L, Gilstad H, Koch S, Harðardóttir GA, Hyppönen H, Marcilly R, Sheik A. Citizens' access to their digital health data in eleven countries-a comparative study. Health-Exploring Complexity: An Interdisciplinary Systems Approach. 2016.

45. Karampela M, Grundstrom C, Isomursu M. Personal health data: accessibility and value in a Danish context. In Proceedings of designing digitalization 2018 (ISD2018 Proceedings). Lund, Sweden: Lund University.

46. Zhu H, Colgan J, Reddy M, Choe EK. Sharing patient-generated data in clinical practices: an interview study. In AMIA Annual Symposium Proceedings 2016 (Vol. 2016, p. 1303). American Medical Informatics Association.

47. Grundstrom C, Karampela M. A transforming insurance company and the 4 types of health data challenges that Arise: a Finnish case study. In Proceedings of the 12th EAI International Conference on Pervasive Computing Technologies for Healthcare 2018 May 21 (pp. 310-317). ACM.

48. Lupton D. You are your data: self-tracking practices and concepts of data. In Lifelogging 2016 (pp. 61-79). Springer VS, Wiesbaden.

49. West P, Van Kleek M, Giordano R, Weal MJ, Shadbolt N. Common barriers to the use of patient-generated data across clinical settings. In proceedings of the 2018 CHI Conference on Human Factors in Computing Systems 2018 Apr 21 (p. 484). ACM.

50. Marcengo A, Rapp A, Cena F, Geymonat M. The falsified self: complexities in personal data collection. In International Conference on Universal Access in Human-Computer Interaction 2016 Jul 17 (pp. 351-358). Springer, Cham.

51. Wicks P. Patient, study thyself. BMC Med. 2018;16:217-9.

52. Mamykina L, Heitkemper EM, Smaldone AM, Kukafka R, ColeLewis HJ, Davidson PG, et al. Personal discovery in diabetes selfmanagement: discovering cause and effect using self-monitoring data. J Biomed Inform. 2017;76:1-8.

53. Karkar R, Zia J, Vilardaga R, Mishra SR, Fogarty J, Munson SA, et al. A framework for self-experimentation in personalized health. J Am Med Inform Assoc. 2015;23(3):440-8.

54. Daskalova N, Desingh K, Papoutsaki A, Schulze D, Sha H, Huang J. Lessons learned from two cohorts of personal informatics selfexperiments. IMWUT. 2017;1(3):46.

55. Denzin NK, Lincoln YS. Handbook of qualitative research. SAGE: Thousand Oaks; 1994. 
56. Moore JF. Predators and prey: a new ecology of competition. Harv Bus Rev. 1993;71(3):75-86.

57. Iansiti M, Levien R. The keystone advantage: what the new dynamics of business ecosystems mean for strategy, innovation, and sustainability. Boston: Harvard Business Press; 2004.

58. Adner R. Match your innovation strategy to your innovation ecosystem. Harv Bus Rev. 2006;84(4):98.

59. Yin RK. Case study research: design and methods. Thousand Oaks: Sage Publications; 2003.

60. Neiman M, Hellström C, Just D, Mattsson C, Fagerberg L, Schuppe-Koistinen I, et al. Individual and stable autoantibody repertoires in healthy individuals. Autoimmunity. 2019;52(1):1-11.

61. Eriksson P, Kovalainen A. Qualitative methods in business research. London: Sage; 2008.

62. Eisner E. The enlightened eye: qualitative inquiry and the enhancement of educational practice. Columbus: Merrill; 1997. p. 1997.

63. Eisenhardt KM, Graebner ME. Theory building from cases: opportunities and challenges. Acad Manag J. 2007;50(1):25-32.

64. Piwek L, Ellis DA, Andrews S, Joinson A. The rise of consumer health wearables: promises and barriers. PLoS Med. 2016;13(2): e1001953.

65. Shih PC, Han K, Poole ES, Rosson MB, Carroll JM. Use and adoption challenges of wearable activity trackers. IConference 2015 Proceedings. 2015 Mar 15.

66. Anderson L, Ostrom AL, Corus C, Fisk RP, Gallan AS, Giraldo M, et al. Transformative service research: an agenda for the future. $\mathrm{J}$ Bus Res. 2013;66(8):1203-10.

67. Graeff TR, Harmon S. Collecting and using personal data: consumers' awareness and concerns. J Consum Mark. 2002;19(4): $302-18$.
68. Frist WH. Connected health and the rise of the patient-consumer. Health Aff. 2014;33(2):191-3.

69. Schreieck M, Wiesche M, Krcmar H. Design and governance of platform ecosystems-key concepts and issues for future research. In Twenty-Fourth European Conference on Information Systems 2016 (ECIS). Istanbul, Turkey.

70. Teece DJ, Pisano G. The dynamic capabilities of firms: an introduction. Ind Corp Chang. 1994;3(3):537-56.

71. Teece DJ, Pisano G, Shuen A. Dynamic capabilities and strategic management. Strateg Manag J. 1997;18(7):509-33.

72. Vargo SL, Lusch RF. Evolving to a new dominant logic for marketing. J Mark. 2004;68(1):1-17.

73. Vargo SL, Lusch RF. Service-dominant logic: continuing the evolution. J Acad Mark Sci. 2008;36(1):1-10.

74. Thakur R, Hsu SH, Fontenot G. Innovation in healthcare: issues and future trends. J Bus Res. 2012;65(4):562-9.

75. Pikkarainen M, Iivari M. Ecosystemic data-driven business models in the context of preventive healthcare: SME perspective. Paper presented at 24th Nordic Academy of Management Conference, 23-25 August, 2017, Bodø, Norway.

76. Fiore-Silfvast B. The frictions and flows of data-intensive transformations: a comparative study of discourses, practices, and structures of digital health in the US and India (Doctoral dissertation); 2014.

Publisher's note Springer Nature remains neutral with regard to jurisdictional claims in published maps and institutional affiliations. 